\title{
Centrifugal gravity-induced BMP4 induces chondrogenic differentiation of adipose- derived stem cells via SOX9 upregulation
}

Yeonsue Jang ${ }^{1,2}$, Hyerin Jung ${ }^{1,2}$, Yoojun Nam ${ }^{1,2}$, Yeri Alice Rim ${ }^{1,2}$, Juryun Kim ${ }^{1,2}$, Sang Hoon Jeong ${ }^{1,2}$ and Ji Hyeon $\mathrm{Ju}^{1,2^{*}}$

\begin{abstract}
Background: Cartilage does not have the capability to regenerate itself. Therefore, stem cell transplantation is a promising therapeutic approach for impaired cartilage. For stem cell transplantation, in vitro enrichment is required; however, stem cells not only become senescent but also lose their differentiation potency during this process. In addition, cytokines are normally used for chondrogenic differentiation induction of stem cells, which is highly expensive and needs an additional step to culture. In this study, we introduced a novel method to induce chondrogenic differentiation of adipose-derived stem cells (ASCs), which are more readily available than bone marrow-derived mesenchymal stem cells(bMSCs), using centrifugal gravity (CG).
\end{abstract}

Methods: ASCs were stimulated by loading different degrees of CG $(0,300,600,1200,2400$, and $3600 \mathrm{~g})$ to induce chondrogenic differentiation. The expression of chondrogenic differentiation-related genes was examined by RT-PCR, real-time PCR, and western blot analyses. The chondrogenic differentiation of ASCs stimulated with CG was evaluated by comparing the expression of positive markers [aggrecan (ACAN) and collagen type II alpha 1 (COL2A1)] and negative markers (COL1 and COL10) with that in ASCs stimulated with transforming growth factor (TGF)- $\beta 1$ using micromass culture, immunofluorescence, and staining (Alcian Blue and Safranin O).

Results: Expression of SOX9 and SOX5 was upregulated by CG (2400 g for $30 \mathrm{~min}$ ). Increased expression of ACAN and COL2A1 (positive markers) was detected in monolayer-cultured ASCs after CG stimulation, whereas that of COL10 (a negative marker) was not. Expression of bone morphogenetic protein (BMP) 4, an upstream stimulator of SOX9, was upregulated by CG, which was inhibited by Dorsomorphin (an inhibitor of BMP4). Increased expression of proteoglycan, a major component of cartilage, was confirmed in the micromass culture of ASCs stimulated with CG by Alcian Blue and Safranin O staining.

Conclusions: Chondrogenic differentiation of ASCs can be induced by optimized CG (2400 g for $30 \mathrm{~min}$ ). Expression of SOX9 is upregulated by CG via increased expression of BMP4. CG has a similar ability to induce SOX9 expression as TGF- $\beta 1$.

Keywords: ACAN, ASCs, BMP4, Centrifugal gravity, Chondrogenic differentiation, COL2A1, Proteoglycan, SOX9

\footnotetext{
* Correspondence: juji@catholic.ac.kr

${ }^{1}$ CiSTEM Laboratory, Convergent Research Consortium for Immunologic

Disease, Seoul St. Mary's Hospital, College of Medicine, The Catholic

University of Korea, Seoul 137-701, South Korea

2Division of Rheumatology, Department of Internal Medicine, Seoul St. Mary's

Hospital, College of Medicine, The Catholic University of Korea, Seoul

137-701, South Korea
} 


\section{Background}

Transplantation of chondrogenically differentiated stem cells may be an advanced treatment for damaged articular cartilage $[1,2]$. Chondrogenic differentiation of stem cells is known to be induced by mechanical stresses [1, 3]. Centrifugal gravity (CG) is one of the easily usable and controllable mechanical stresses and is generated by centrifugation. However, little is known about whether CG can induce chondrogenic differentiation of stem cells.

Impaired articular cartilage cannot be autonomously (naturally) cured. Human adult articular cartilage has a very limited ability to regenerate due to the lack of a precursor cell supply [4]. To provide precursor cells to articular cartilage via the bloodstream, microfracture surgery has been used; however, it often causes fibrocartilage leading to cartilage degeneration [5]. As an alternative, autologous chondrocyte implantation (ACI) showed a satisfactory clinical outcome [6-8]. However, ACI has some disadvantages such as transplanted cartilage separation, limited sources for articular cartilage isolation, and cartilage degeneration $[6,9,10]$. Most recently, stem cells have been transplanted to regenerate damaged articular cartilage [11]. Under the optimized in vitro culture condition, stem cells can be differentiated into chondrocytes, a major component of cartilage [12, 13]. In addition, bone marrow-derived mesenchymal or adiposederived stem cells (bMSCs and ASCs) are easily isolated from bone marrow and fat, respectively [14-16]. Despite the aforementioned advantages, the method of stem cell transplantation needs to be improved. As a substitute, bMSCs are now used, but they are hardly sufficiently collected and can unexpectedly differentiate to any lineage other than chondrocyte during in vitro cultivation $[17,18]$. For these reasons, we wanted to trigger chondrogenic differentiation of ASCs, relatively abundant stem cells, before transplantation. This may reduce unexpected lineage differentiation of stem cells. Considering these concerns, the period from cell isolation to transplantation should be shortened to increase the success rate of cartilage regeneration.

CG may induce chondrogenic differentiation of stem cells. Mechanical stresses induce chondrogenic phenotypes in various cells. Hydrostatic pressure induces chondrogenic phenotypes in synovium-derived progenitor cells via the MAP kinase/JNK pathway [19]. Mechanical compression induces human bMSC chondrogenesis by upregulating chondrocytic genes [20]. Shear stress contributes to chondrogenesis-related extracellular matrix (ECM) expression in human bMSCs [21]. It was previously reported that CG induces gene expression in cells. In lung epithelial carcinoma cells, expression of interleukin- $1 \beta$ is upregulated by centrifugation [22]. Therefore, as a mechanical stress, CG may induce chondrocytic gene expression in stem cells.

Considering that chondrogenic differentiation of stem cells is induced by mechanical stresses, CG may have a similar ability to induce chondrogenic differentiation of stem cells as transforming growth factor (TGF)- $\beta 1$, a growth factor normally used for in vitro chondrogenesis of stem cells. Therefore, application of CG may make the stem cells produce chondrogenic transcription factors and ECM proteins. In this study, we demonstrated that CG induced chondrocytic gene expression in human ASCs and compared the effects of CG on chondrogenesis with those of TGF- $\beta 1$.

\section{Methods}

\section{Stem cell acquisition and culture}

Human ASCs obtained from abdomen fat $(\mathrm{n}=3$, age 30 54 years) were purchased from Catholic MASTER Cells (Seoul, Korea). All experiments were performed with the ASCs from three different donors (age 30-54 years). The research protocol was granted by the Institutional Review Board of Seoul St. Mary's Hospital. The cells (P2-3, 1.5$3 \times 10^{3} / \mathrm{cm}^{2}$ ) were cultured in growth medium, which consists of low-glucose Dulbecco's modified Eagle medium (DMEM; Gibco, Grand Island, NY, USA) supplemented with $10 \%$ fetal bovine serum (FBS; Gibco) and 1\% antibiotic-antimycotic solution (Invitrogen, Grand Island, NY, USA) until the cells reach $80-90 \%$ confluency in a humidified $5 \% \mathrm{CO}_{2}$ incubator at $37{ }^{\circ} \mathrm{C}$.

\section{CG loading}

All experiments were performed with 2-3 passaged ASCs. ASCs (P2-3, $1 \times 10^{5}$ cells $/ \mathrm{mL}$ ) were transferred to a new $15 \mathrm{~mL}$ conical tube and centrifuged at various gravitational forces $(0,300,600,1200,2400$, and $3600 \mathrm{~g})$ for various durations $(0,5,15,30$, and $60 \mathrm{~min})$ using a centrifuge (1580MGR, Gyrozen, Seoul, South Korea). After CG loading, the cells were re-plated onto a $60 \mathrm{~mm}$ culture dish in monolayer and incubated until the desired time points in growth medium.

\section{Chondrogenic differentiation}

Chondrogenic differentiation was modified from previously reported [23]. For three-dimensional pellet culture, CG-stimulated ASCs were resuspended in defined chondrogenic differentiation medium (CDM; high-glucose DMEM supplemented with 1\% FBS, 1\% ITS + Premix, $100 \mathrm{nM}$ dexamethasone, $1 \times$ MEM Non-Essential Amino Acid solution, $50 \mu \mathrm{g} / \mathrm{mL}$ L-proline, and $1 \%$ penicillin/ streptomycin). Non-treated cells were resuspended in growth media as a negative control. As a positive control, non-treated cells in a $15 \mathrm{~mL}$ conical tube were resuspended in CDM containing $10 \mathrm{ng} / \mathrm{mL}$ TGF- $\beta 1$. The tube was placed in an upright position, and cells were incubated at $37{ }^{\circ} \mathrm{C}$ in a humidified incubator containing $5 \% \mathrm{CO}_{2}$. The medium was changed every 2 or 3 days for 2-3 weeks. L-ascorbic acid 2-phosphate has a short halflife, therefore it was provided at the concentration of 50 $\mathrm{ug} / \mathrm{ml}$ every media change $[24,25]$. 


\section{Cell viability assay}

Cells stimulated with or without CG were seeded onto a 96-well plate. After $24 \mathrm{~h}$, cell viability was investigated using CCK-8 solution (Dojindo Molecular Technologies, Rockville, MD, USA) according to the manufacturer's manual. Briefly, CCK-8 solution was added to each well to a final concentration of $10 \%$. After incubation for $4 \mathrm{~h}$, absorbance was measured at $450 \mathrm{~nm}$ using an ELISA reader (VersaMax, Molecular Devices, Sunnyvale, CA, USA).

\section{Histological analysis}

The pelleted cells were harvested and then histologically analyzed at 21 days. Micromass pellets were washed twice with $1 \times$ phosphate-buffered saline (PBS) and fixed for $24 \mathrm{~h}$ in $10 \%$ formalin. After fixation, micromass pellets were paraffin-embedded and sectioned ( $5 \mu \mathrm{m}$ thick). Micromass pellet sections were deparaffinized, rehydrated, and then washed with PBS. To validate chondrogenic differentiation, sectioned micromasses were stained with $1 \%$ Safranin O solution or 3\% Alcian Blue for $10 \mathrm{~min}$ and counterstained with hematoxylin and eosin solution (Sigma-Aldrich, St. Louis, MO, USA) [23]. The sections were mounted, and images were acquired using an inverted fluorescence microscope (IX-71, Olympus, Center Valley, PA, USA).

\section{Immunofluorescence assay}

Rehydrated micromass pellet sections were deparaffinized, rehydrated, and washed twice in buffer. The slides were incubated in $3 \% \mathrm{H}_{2} \mathrm{O}_{2}$ (prepared in $1 \times$ PBS) for 15 min and washed with tap water for $15 \mathrm{~min}$. The slides were blocked with blocking buffer (10\% normal goat serum prepared in PBS) for $1 \mathrm{~h}$ [26]. Anti-collagen type II (COL2A1) (1:100; Abcam, Cambridge, MA, USA) and anti-aggrecan (ACAN) (1:200; GeneTex, Irvine, CA, USA) primary antibodies were applied and incubated according to the manufacturer's recommended protocol, and the slides were washed four times in buffer. The slides were incubated with a fluorochrome-conjugated secondary antibody diluted in $5 \%$ normal goat serum for $1 \mathrm{~h}$ at room temperature in the dark and then washed three times in 1× PBS for $5 \mathrm{~min}$ each in the dark. The slides were incubated with DAPI (1 $\mu \mathrm{g} / \mathrm{mL}$; Molecular Probes, Waltham, MA, USA) for $10 \mathrm{~min}$, washed twice with $1 \times$ PBS for 5 min each, and then visualized using fluorescence microscopy.

\section{Quantitative and semi-quantitative PCR analysis}

Total RNA was extracted from stem cells with or without CG stimulation using TRIzol reagent (Invitrogen, Waltham, MA, USA) according to the manufacturer's protocol. Total RNA $(1 \mu \mathrm{g})$ was reverse-transcribed using a RevertAid $^{\mathrm{ma}}$ First Strand cDNA Synthesis Kit (Fermentas, Burlington, ON, Canada). For quantitative real-time PCR, cDNA (25 ng) was amplified using SYBR ${ }^{\circ}$ Green PCR Master Mix (Applied Biosystems, Carlsbad, CA, USA).
Primers for GAPDH (P267613), SRY (sex-determining region Y)-box (SOX) 5 (P209528), 5'-AACAAGCACA GATCCCCATTG(dTdT)-3' (sense) and 5'-ACACCGTAAGTGCTCTGGATA(dTdT)-3' (antisense), SOX6 (P1 4 2525), 5' - AAGGCTAAAGGGCCTAAGTGA(dTdT)3' (sense) and 5' - TTGATGGCATCTTTGCTCCAG(dTd T)-3' (antisense) SOX9 (P232240), 5' - CCACCTTCACCTACATGAACC(dTdT)-3' (sense) and 5'-CTGTGTGT AGACGGGTTGTTC(dTdT)-3' (antisense) and bone mo rphogenetic protein (BMP) 4 (P196415) 5'-GACACGG TGGGAAACTTTTGA(dTdT)-3' (sense) and 5'-GGTA ACGATCGGCTAATCCTG(dTdT)-3' (antisense) were purchased from Bioneer (Daejeon, South Korea). Realtime PCR was performed using a real-time system (Roche, Indianapolis, IN, USA). Mean cycle threshold values from triplicate experiments were used to calculate gene expression normalized to GAPDH as an internal control. For semi-quantitative PCR, $25 \mathrm{ng}$ of cDNA was amplified using Taq polymerase and designed primers. The primer sequences were as follows: COL2A1, 5'-GGCAATAGCAGGTTCACGTACA-3' (sense) and 5'-CGATAACAG TCTTGCCCCACTT-3' (antisense); ACAN, 5'-GTGCC TATCAGGACAAGGTCT-3' (sense) and 5'-GATGCCT TTCACCACGACTTC-3' (antisense); BMP2, 5'-CCCA GCGTGAAAAGAGAGAC-3' (sense) and 5'-GAGAC CGCAGTCCGTCTAAG-3' (antisense); COL1A1, 5'-CC CCTGGAAAGAATGGAGATG-3' (sense) and $5^{\prime}$-TCC AAACCACTGAAACCTC TG-3' (antisense); COL10A1, 5'-CAGTCATGCCTGAGGGTTTT-3' (sense) and 5'-G GGTCATAATGCTGTTG CCT-3' (antisense); and TGF$\beta 1,5^{\prime}$-TCCTGCTTCTCATGGCCA-3' (sense) and 5' CCTCAGCTGCACTTGTA G-3' (antisense). The intensity of RT-PCR bands was quantified using ImageJ (1.40).

\section{Western blot analysis}

For protein extraction, whole cells were lysed in RIPA buffer (50 mM Tris, pH 7.4, $150 \mathrm{mM} \mathrm{NaCl}, 5 \mathrm{mM}$ EDTA, $30 \mathrm{mM} \mathrm{NaF}, 1 \mathrm{mM} \mathrm{Na} \mathrm{VO}_{4}, 0.1 \mathrm{mM}$ PMSF, protease inhibitors, and $1 \%$ Nonidet-P40). The supernatant was harvested and concentrated using a Vivaspin Turbo 15 (Sartorius Stedim, Gottingen, Germany). For normalization, the same number of cells was plated after CG loading or without CG loading for control, and the GAPDH expression of each condition was investigated using western blot analysis. Protein lysates $(30 \mu \mathrm{g})$ and concentrated supernatants were resolved by $10-12 \%$ SDS-PAGE, transferred to polyvinylidene difluoride membranes (Amersham Pharmacia Biotech, Piscataway, NJ, USA), and then probed with primary antibodies against SOX9 (EMD Millipore, Billerica, MA, USA), BMP4 (Santa Cruz Biotechnology, Inc., Dallas, Texas USA), and GAPDH (Abcam). After extensive washing, primary antibodies were detected by peroxidase-linked IgG (1:5000; Abcam) and visualized using an ECL kit (WESTSAVE GOLD, AbFrontier, Geumcheon-gu, Seoul, 
South Korea). The intensity of western blot bands was quantified using ImageJ (1.40).

\section{Statistical analysis}

All experiments were separately performed at least three times. Statistical analysis was performed using a one-way analysis of variance (ANOVA) with post hoc Bonferroni correction. The statistical comparison at the same time points between two groups was performed using twoway ANOVA. Data are presented as the mean \pm standard deviation. For all tests, $p<0.05$ was considered to be statistically significant.

\section{Results}

CG increased SOX9 expression in ASCs

SOX9 is a master regulator of chondrogenic differentiation [27]. To determine what degree of CG force is suitable to induce SOX9 upregulation, ASCs were stimulated with different degrees of CG (0,300, 600, 1200, 2400, and $3600 \mathrm{~g}$ ) for $15 \mathrm{~min}$. After stimulation, the ASCs were re-seeded onto a culture plate and then cultured for $24 \mathrm{~h}$. SOX9 mRNA expression was significantly increased at 600 and $2400 \mathrm{~g}$, and it was approximately threefold higher at $2400 \mathrm{~g}$ than in the control (ASCs not loaded with CG) (Fig. 1a). CG-induced SOX9 expression did not show a linear increase. Next, to optimize the CG loading time, SOX9

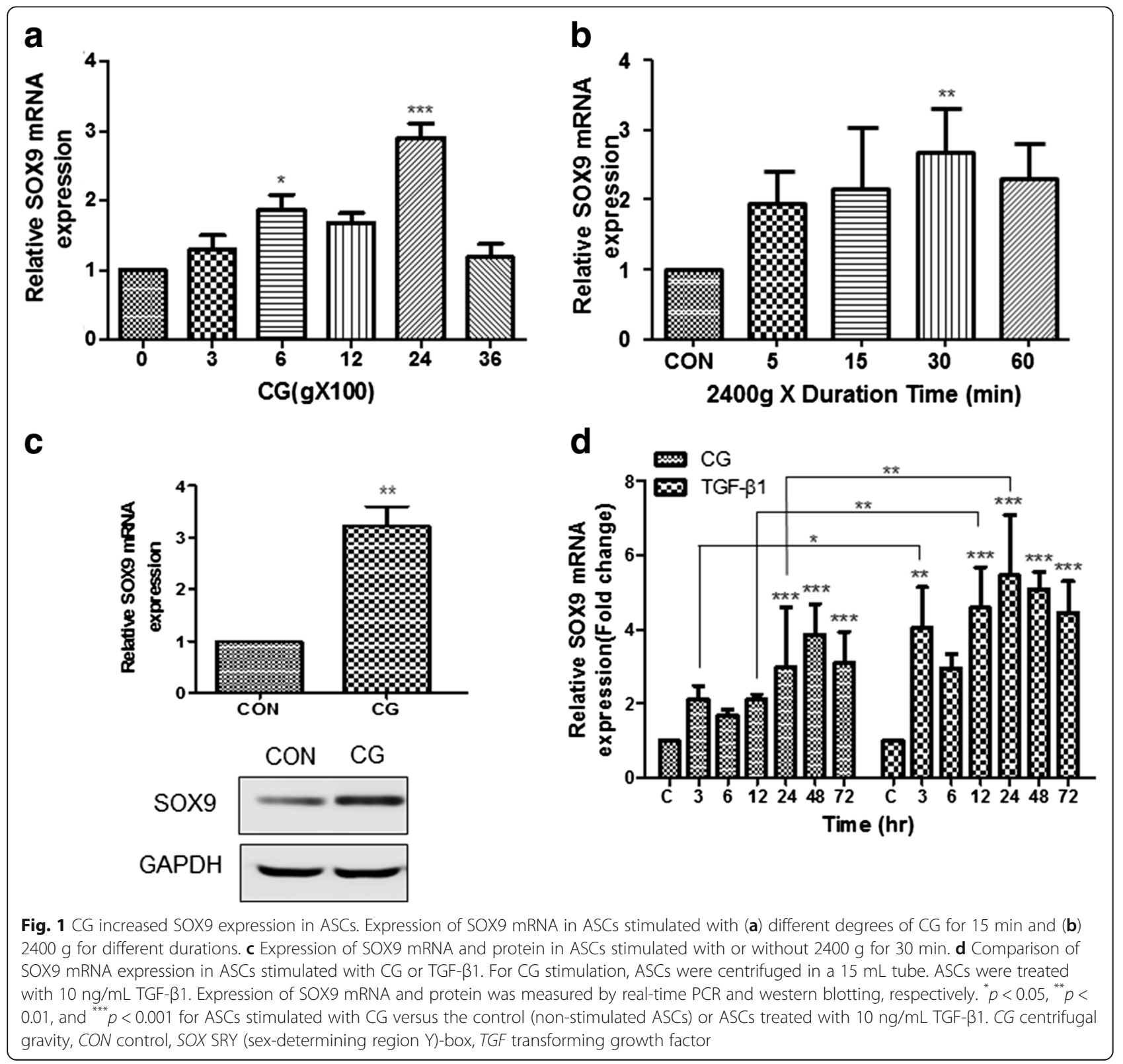


expression in ASCs stimulated with $2400 \mathrm{~g}$ was compared among different time points $(0,5,15,30$, and $60 \mathrm{~min})$. The expression of SOX9 mRNA was not significantly increased by CG at 5,15 , and $60 \mathrm{~min}$, whereas it was significantly upregulated at $30 \mathrm{~min}$ (Fig. 1b). Because CG may affect cell viability, ASC viability was investigated with different loading durations. ASC viability was increased a little after CG stimulation for 5, 15, 30, and 60 min compared to the control, and it was not significantly different between each loading duration time (Additional file 1: Figure S1). Corresponding to SOX9 upregulation by CG stimulation, the expression of SOX9 protein was increased in ASCs centrifuged at $2400 \mathrm{~g}$ for $30 \mathrm{~min}$ compared with the control (Fig. 1c). TGF- $\beta 1$ has been used to induce increased expression of SOX9 $[28,29]$. Therefore, SOX9 mRNA expression in ASCs stimulated by the optimized CG conditions (2400 $\mathrm{g}$ for $30 \mathrm{~min}$ ) was compared with that in ASCs treated with $10 \mathrm{ng} / \mathrm{mL}$ TGF- $\beta 1$. Upregulation of SOX9 mRNA was observed from $3 \mathrm{~h}$ after stimulation with CG or TGF- $\beta 1$, gradually increased by $24 \mathrm{~h}$, and maintained up to $72 \mathrm{~h}$ (Fig. 1d).

\section{CG-induced SOX9 upregulation was associated with chondrogenic differentiation}

SOX5 and SOX6 are co-factors involved in chondrogenic differentiation [27, 30]. Expression of SOX5 mRNA was upregulated more than twofold at $24 \mathrm{~h}$ after CG stimulation and was maintained up to $48 \mathrm{~h}$ (Fig. 2a). On the other hand, expression of SOX6 mRNA was not significantly upregulated by CG stimulation. COL2A1 and ACAN are major components of cartilage as ECM proteins expressed in chondrocytes, and their expression is regulated by SOX9. Expression of ACAN and COL2A1 mRNA was increased by CG stimulation. In particular, COL2A1 expression was greatly increased by CG stimulation (Fig. 2b). In vitro chondrogenic differentiation may be able to induce fibrotic cartilage or hypertrophic differentiation, which inhibits chondrogenic differentiation [31-33]. Therefore, expression of COL1 (a marker of fibrocartilage) and COL10 (a marker of hypertrophy) was examined in ASCs with or without optimized CG stimulation [34-36]. Protein expression of COL1 was slightly increased by CG stimulation, whereas that of COL10 was dramatically decreased (Fig. 2c).

\section{CG induced SOX9 upregulation via increased expression of BMP4}

BMPs enhance the chondrogenic differentiation induction effect of TGF- $\beta 1$ [37-39]. In particular, BMP2 and BMP4 are involved in SOX9 expression [40, 41] and are upregulated by a mechanical stress [42]. Expression of BMP2 mRNA was upregulated approximately twofold by CG stimulation, but it differed little among the different CG conditions (Fig. 3a). On the other hand, expression of BMP4 was gradually upregulated by CG (300-2400 g) and showed the greatest increase at $2400 \mathrm{~g}$. Expression of TGF- $\beta 1$ mRNA was not changed by CG stimulation. Because BMP4 mRNA expression was mainly affected by CG stimulation, its duration was further investigated. Upregulation of BMP4 mRNA was detected from $3 \mathrm{~h}$ after CG stimulation, peaked at $24 \mathrm{~h}$, and decreased a little at $48 \mathrm{~h}$ (Fig. 3b). Based on the duration of BMP4 mRNA expression, BMP4 protein expression was further examined

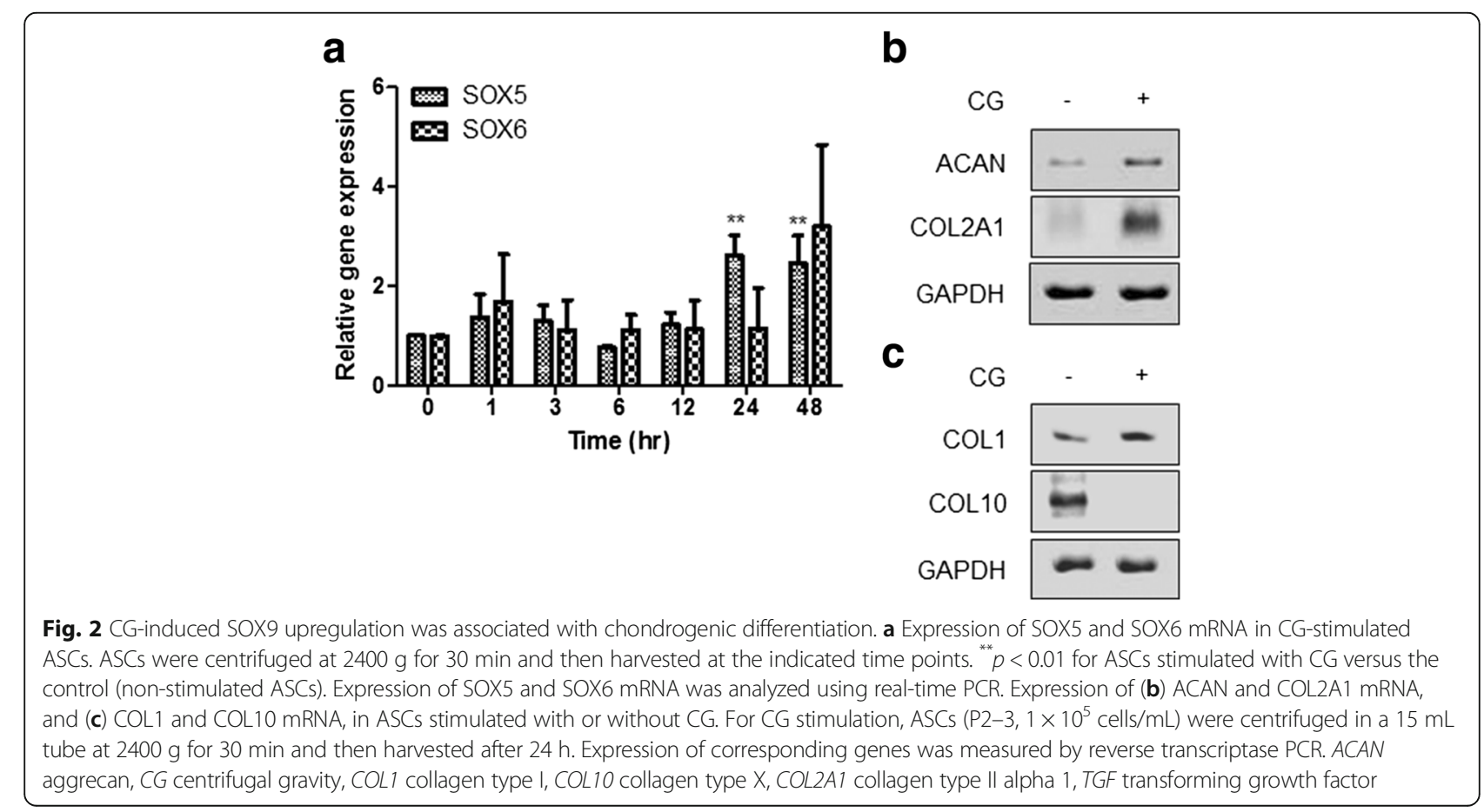

b 
at 0,24 , and $48 \mathrm{~h}$. Unlike BMP4 mRNA expression, BMP4 protein expression was much higher at $48 \mathrm{~h}$ than at $24 \mathrm{~h}$ (Fig. 3c). To confirm that increased expression of BMP4 was associated with CG-induced SOX9 upregulation, changes in SOX9 mRNA and protein expression in ASCs were investigated in the presence or absence of CG stimulation, BMP4 recombinant protein, and/or Dorsomorphin (a BMP4 inhibitor). SOX9 upregulation depended on both CG and BMP4. CG-upregulated SOX9 expression was decreased by Dorsomorphin ( $25 \mathrm{nM}$ ) (Fig. 3d).

CG-stimulated ASCs showed chondrogenic characteristics To determine whether CG-stimulated ASCs show a similar level of chondrogenic differentiation as TGF- $\beta 1$-treated ASCs, marker molecule expression was compared between micromass cultures of ASCs stimulated with CG or TGF$\beta 1$. mRNA expression of marker molecules (ACAN and COL2A1 as positive markers; COL1 and COL10 as negative markers) was evaluated after 14 days of chondrogenic differentiation. Compared with the control (non-stimulated micromass culture), ACAN mRNA in micromass cultures was upregulated by TGF- $\beta 1$, but not by CG. COL2A1 mRNA was upregulated by both CG and TGF$\beta 1$, but CG was less effective than TGF- $\beta 1$. COL1 mRNA was affected by neither CG nor TGF- $\beta 1$. COL10 mRNA was largely downregulated by CG, but was not affected by TGF- $\beta 1$ (Fig. 4a). Chondrogenic-specific staining such as Alcian Blue and Safranin O demonstrated that CG stimulation induced a similar level of chondrogenic differentiation of ASCs as TGF- $\beta 1$. However, the micromass of CGstimulated ASCs was smaller than that of TGF- $\beta 1$-treated ASCs (Fig. 4b). To confirm that CG induces chondrogenic phenotypes, the expression of positive markers was further evaluated after 21 days of chondrogenic differentiation using specific antibodies against ACAN and COL2A1. ACAN and COL2A1 proteins were both increased in the micromass of CG-stimulated ASCs, similar to that of TGF- $\beta 1$-treated ASCs (Fig. 4c).

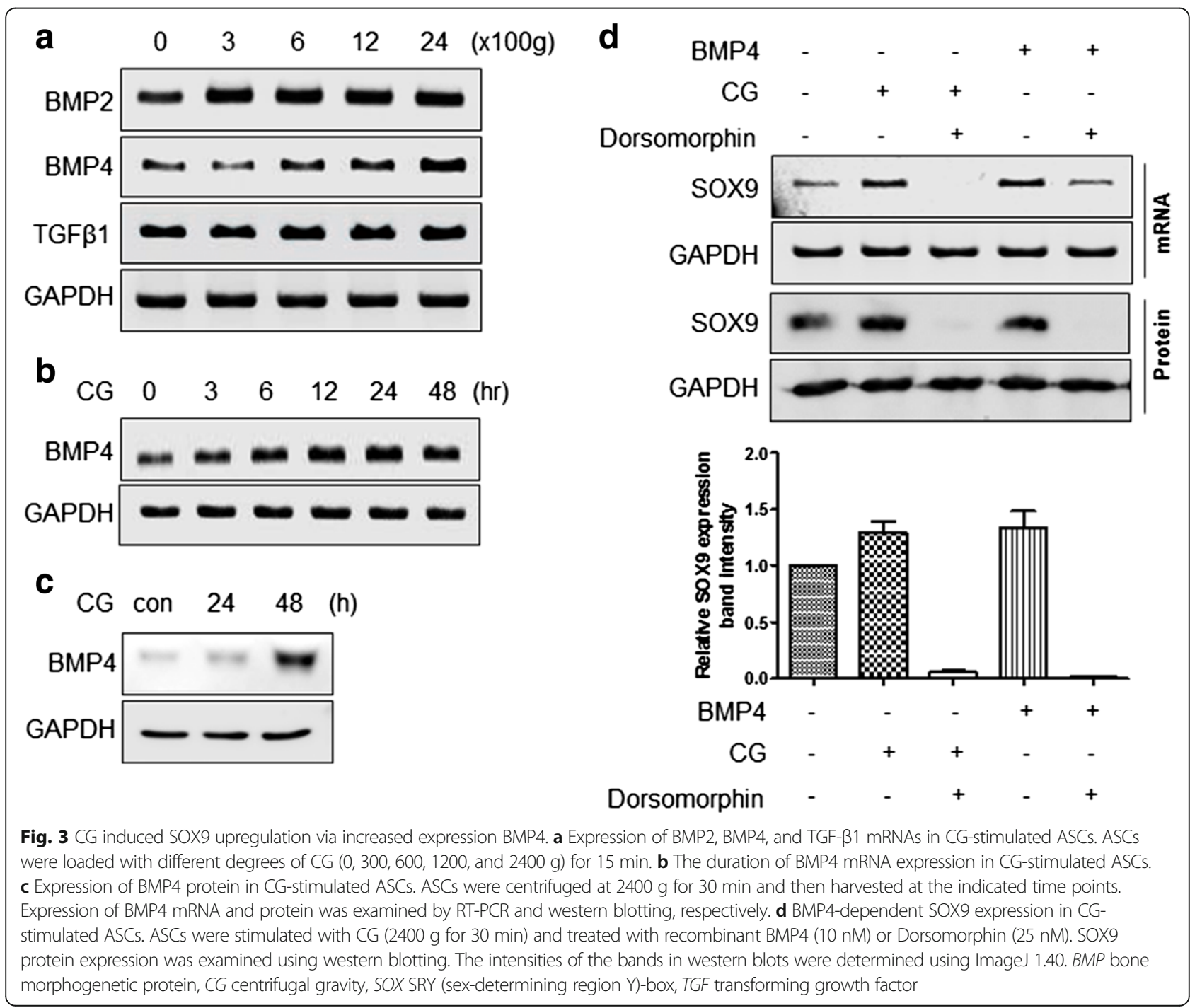




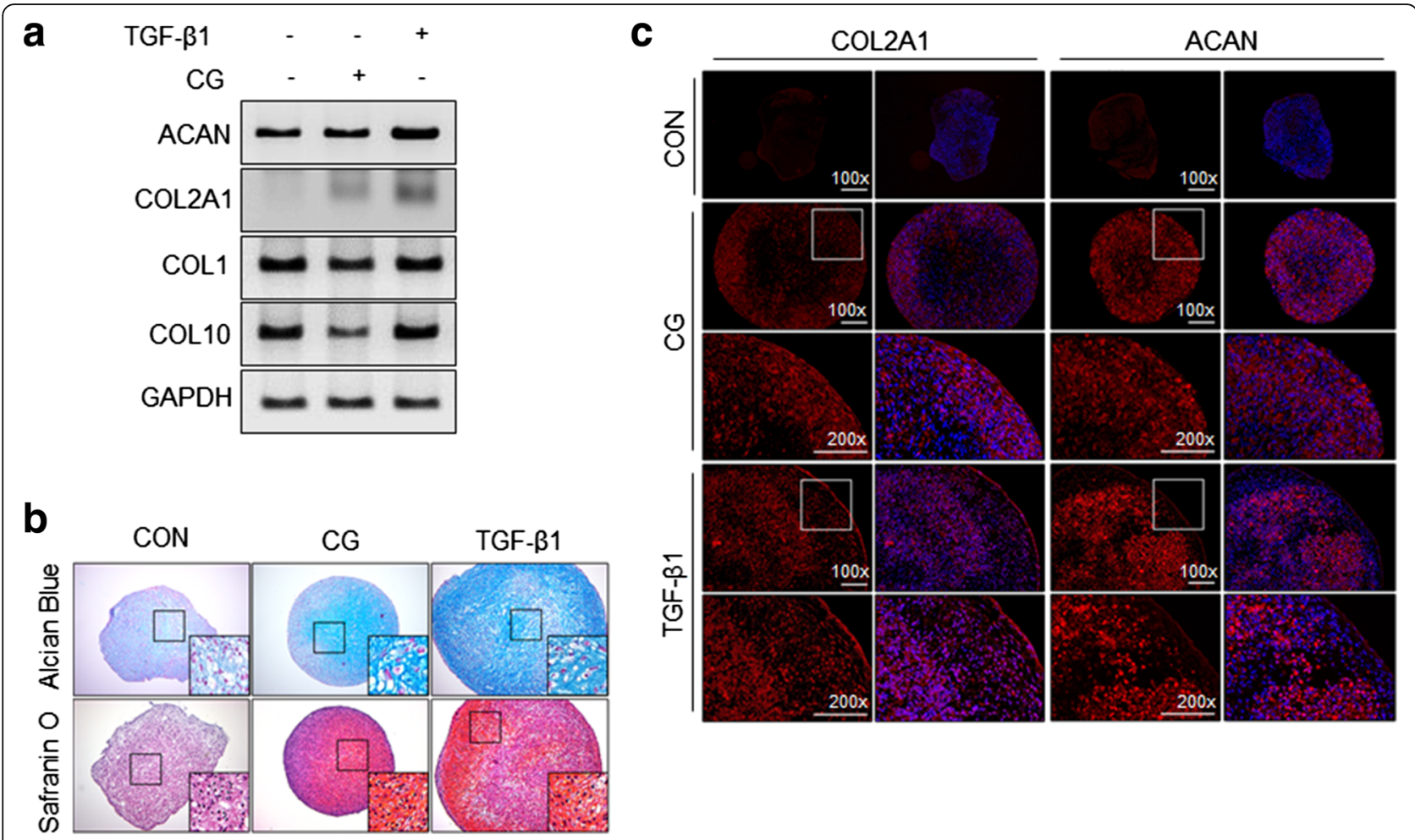

Fig. 4 CG-stimulated ASCs showed chondrogenic characteristics. a Expression of chondrogenic differentiation markers in ASC micromass cultures. Total RNA was extracted from ASC micromass cultures at 14 days. Expression of each marker mRNA was examined using RT-PCR. b Chondrogenic ECM staining of ASC micromass cultures. Sections of ASC micromass cultures at 21 days were stained with Alcian Blue or Safranin O. c Expression of ACAN and COL2A1 proteins in ASC micromass cultures. Sections of ASC micromass cultures at 21 days were stained with a fluorescence (phycoerythrin)-conjugated anti-ACAN or COL2A1 antibody (red: ACAN or COL2A1, blue: DAPI). ASCs were stimulated with CG (2400 g for $30 \mathrm{~min})$ or TGF- $\beta 1(10 \mathrm{ng} / \mathrm{mL})$ and then used for micromass culture. The control was not stimulated with CG or TGF- $\beta 1$. ACAN aggrecan, CG centrifugal gravity, COL1 collagen type I, COL10 collagen type X, COL2A1 collagen type II alpha 1, CON control, TGF transforming growth factor

\section{Discussion}

Centrifugation is a common process in cell harvest and isolation. Therefore, chondrogenic differentiation of stem cells by CG stimulation may be regarded as an unnecessary step because BMP4 and SOX9 upregulation can be induced during cell harvest or isolation. However, expression of SOX9 mRNA was not significantly upregulated at $300 \mathrm{~g}$ (Fig. 1a). In general, centrifugation at less than $200 \mathrm{~g}$ is used for cell harvest and isolation. It was previously reported that centrifugation at $150-600 \mathrm{~g}$ for $5 \mathrm{~min}$ can induce chondrogenic differentiation [43-45]. However, such a degree of gravitational force was often used to form a spheroid pellet, which assists the chondrogenic differentiation of stem cells. To induce a similar level of SOX9 expression as that observed upon TGF- $\beta 1$ treatment, the degree of CG should be around $2400 \mathrm{~g}$ and its duration should be $30 \mathrm{~min}$ (Fig. 1d). Considering that a centrifuge is a common laboratory device and that $2400 \mathrm{~g}$ is easily generated by centrifugation, CG may be an excellent substituent for cytokines, especially TGF- $\beta 1$, in the chondrogenic differentiation induction of stem cells.
As a rapid response gene, SOX9 expression was significantly increased at $30 \mathrm{~min}$ after centrifugation (Fig. 1a). However, for potential clinical application, the duration of CG-induced SOX9 expression was further examined since the longer expression the more advantageous for cartilage generation. As shown in Fig. 1a and b, SOX9 expression at $24 \mathrm{~h}$ was approximately three times higher than the control. To objectify the effect of CG on chondrogenic differentiation induction, CG-stimulated ASCs were compared with TGF- $\beta 1$-treated ones. TGF- $\beta 1$ is a widely used chondrogenic inducer [46, 47]. In Fig. 1d, SOX9 expression in the ASCs stimulated by CG was generally lower than that by TGF- $\beta 1$. However, CG-stimulated ASCs showed an average of twofold higher expression of SOX9 than the control ASCs (not stimulated by CG) from $24 \mathrm{~h}$ to $72 \mathrm{~h}$, which may mean that CG stimulation is useful to induce the chondrogenic differentiation of ASCs. Indeed, positive markers for chondrogenic differentiation (ACAN and COL2A1) were upregulated by CG in monolayer cultured ASCs, whereas a negative marker (COL10) was downregulated (Fig. 2b and c). The expression of COL10 
in the pellet culture of CG-stimulated ASCs was not matched to that of monolayer cultured ones. In the case of monolayer cultured cells, COL10 was not expressed by CG at all: CG downregulated the expression of COL10. On the other hand, in chondrogenic differentiation culture, COL10 was expressed in the cells exposed to CG, but not as high as the control and TGF- $\beta 1$-treated group. According to previous reports, the expression of COL10 was increased during in vitro chondrogenic differentiation [48]. Considering the lower expression level of COL10 in the in vitro chondrogenic differentiation culture of CGstimulated ASCs than those of the control and TGF- $\beta 1$ treated group, CG may have a suppressive effect on COL10 expression. Similar to the traditional culture, chondrogenic-specific matrices were positively stained in the pellet of CG-stimulated ASCs compared to the control (Fig. 4b). Interestingly, the pellet size was markedly larger in the traditional method of pellet culture (namely, TGF$\beta 1$-treated ASCs) than that of CG-stimulated ASCs. This may be caused by more stimulation in the traditional method. For the traditional method of culture, medium was changed every other day with fresh TGF- $\beta 1$, a chondrogenic differentiation inducer for 2-3 weeks. On the other day, fresh medium was provided for the CG group as the traditional method group, but CG stimulation was not (CG was provided only once before pellet culture). As a growth factor, TGF- $\beta 1$ can increase cell proliferation as well as chondrogenic differentiation. Therefore, the pellet size of the traditional method group was bigger than that of the CG group. In Fig. 4c, the matrix deposition pattern of the CG group was perichondrial distribution, whereas that of the traditional method group was uniform distribution. This difference may be associated with the level of matrix protein expression. The multiple stimulation of TGF- $\beta 1$ may induce higher expression of matrix protein than CG stimulation, which leads to uniform distribution in the traditional method group. Since the potential application of CG-stimulated ASCs to 1-day surgery was considered, we provided CG stimulation only once, and compared the chondrogenic differentiation ability of CGstimulated ASCs with that of the traditional method group (continuously stimulated with TGF- $\beta 1$ ).

BMPs are associated with chondrogenic differentiation, especially to enhance the function of TGF- $\beta 1$ in chondrogenic differentiation induction $[37,39]$. In the present study, BMP4 was upregulated by CG (Fig. 3a). BMP4 is upregulated by mechanical stress [42] and is also involved in SOX9 expression. Based on our data, CG may be a good substituent for TGF- $\beta 1$ in that it can be easily generated in a general laboratory environment and requires no expense. For a better understanding of CG-increased BMP4 expression, it should be further studied how CG induces increased expression of BMP4. Furthermore, for clinical applications, the effect of CG- stimulated ASCs on cartilage regeneration needs to be evaluated in an in vivo model.

In our study, we induced chondrogenic differentiation of ASCs using centrifugation, properly speaking, the gravity force generated by centrifugation. Centrifugation is a way to put gravity force on ASCs. Therefore, any type of centrifugation can be used to induce chondrogenic differentiation of ASCs. A more important thing than the type of centrifugation may be the degree and duration time of centrifugal gravity force. Based on our results, centrifugation at $2400 \mathrm{~g}$ for $30 \mathrm{~min}$ was the most optimal for the induction of SOX9 expression in ASCs. Among the degrees of CG tested, SOX9 expression was induced only at $600 \mathrm{~g}$ and $2400 \mathrm{~g}$, which may mean that SOX9 expression is not proportional to the degree of CG. In a previous study, mechanical compression induced the alteration of microRNA expression, which was not proportional to the degree of compression [49]. As shown in Fig. 1a, SOX9 expression was not increased at $3600 \mathrm{~g}$ at all. This may be mechanobiological physiology. Interestingly, according to previous studies, mechanical stresses were associated with osteogenic differentiation. Considering that gravity force is one of mechanical stresses, a different degree of centrifugation may induce osteogenic differentiation [50]. In addition, adipogenic and fibrogenic differentiation may be associated with centrifugation. It was reported that mechanical stress suppressed adipogenic differentiation [51], whereas it induced fibrogenic differentiation [52]. Accordingly, CG stimulation may be a useful tool for various lineaged differentiation of stem cells as well as chondrogenic differentiation.

\section{Conclusions}

In this study, we demonstrated that CG can induce chondrogenic differentiation of ASCs via increased expression of BMP4 and SOX9. Our data suggest that CG-stimulated ASCs may improve stem cell-based cartilage regeneration regarding convenience and cost.

\section{Additional file}

Additional file 1: Figure S1. Comparison of the viabilities of ASCS stimulated with CG for different durations. ASCs were stimulated with CG $(2400 \mathrm{~g})$ for different durations $(0,5,15,30$, and $60 \mathrm{~min})$ and then plated onto a 96-well tissue culture plate. At $24 \mathrm{~h}$ after CG stimulation, ASCs were incubated with CCK- 8 for $4 \mathrm{~h}$ and then their viabilities were determined by measuring absorbance at $450 \mathrm{~nm}$ using an ELISA reader. All experiments were performed in triplicate. ${ }^{* * *} p<0.001$ for ASCs stimulated with CG versus the control (non-stimulated ASCs). (TIF 1026 kb)

\section{Abbreviations}

ACAN: aggrecan; ACl: autologous chondrocyte implantation; ASC: adiposederived stem cell; BMP: bone morphogenetic protein; CDM: chondrogenic differentiation medium; CG: centrifugal gravity; COL2A1: collagen type II alpha 1; DMEM: Dulbecco's modified Eagle medium; ECM: extracellular matrix; FBS: fetal bovine serum; MSC: mesenchymal stem cell; PBS: phosphate-buffered saline; SOX: SRY (sex-determining region Y)-box; TGF: transforming growth factor 


\section{Acknowledgements}

Not applicable.

\section{Funding}

This research was supported by a grant of the Korea Health Technology R\&D Project through the Korea Health Industry Development Institute (KHIDI), funded by the Ministry of Health and Welfare, Republic of Korea (grant number: HI14C2116 and HI16C2177).

\section{Availability of data and materials}

The datasets supporting the conclusions of this article are included within the article and its additional file.

\section{Authors' contributions}

YJ contributed to the experimental conception and design, performed all the experiments, analyzed and interpreted the data, and wrote the manuscript. $\mathrm{H}$. performed some of the experiments and data acquisition. YN analyzed and interpreted the data. YR analyzed and interpreted the data. JK analyzed and interpreted the data. SHJ analyzed and interpreted the data. JHJ contributed to the study design, interpretation, and revision of the manuscript. All authors read and approved the final version of the manuscript.

\section{Competing interests}

The authors declare that they have no competing interests.

\section{Consent for publication}

Not applicable.

\section{Ethics approval and consent to participate}

This study protocol was approved by the institutional review board of The Catholic University of Korea (KC16EAME0162) and performed according to National Institutes of Health $(\mathrm{NIH})$ guidelines.

Received: 10 September 2016 Revised: 9 November 2016 Accepted: 19 November 2016 Published online: 08 December 2016

\section{References}

1. O'Conor CJ, Case N, Guilak F. Mechanical regulation of chondrogenesis. Stem Cell Res Ther. 2013;4:61.

2. Nejadnik H, Diecke S, Lenkov OD, Chapelin F, Donig J, Tong X, Derugin N, Chan RC, Gaur A, Yang F, et al. Improved approach for chondrogenic differentiation of human induced pluripotent stem cells. Stem Cell Rev. 2015;11:242-53.

3. Juhasz T, Matta C, Somogyi C, Katona E, Takacs R, Soha RF, Szabo IA, Cserhati C, Szody R, Karacsonyi Z, et al. Mechanical loading stimulates chondrogenesis via the PKA/CREB-Sox9 and PP2A pathways in chicken micromass cultures. Cell Signal. 2014;26:468-82.

4. Mandelbaum BR, Browne JE, Fu F, Micheli L, Mosely Jr JB, Erggelet C, Minas T, Peterson L. Articular cartilage lesions of the knee. Am J Sports Med. 1998; 26:853-61.

5. Murawski CD, Foo LF, Kennedy JG. A review of arthroscopic bone marrow stimulation techniques of the talus: the good, the bad, and the causes for concern. Cartilage. 2010;1:137-44.

6. Knutsen $\mathrm{G}$, Drogset JO, Engebretsen L, Grontvedt T, Isaksen V, Ludvigsen TC, Roberts S, Solheim E, Strand T, Johansen O. A randomized trial comparing autologous chondrocyte implantation with microfracture. Findings at five years. J Bone Joint Surg Am. 2007;89:2105-12.

7. Grande DA, Pitman MI, Peterson L, Menche D, Klein M. The repair of experimentally produced defects in rabbit articular cartilage by autologous chondrocyte transplantation. J Orthop Res. 1989;7:208-18.

8. Vanlauwe J, Saris DB, Victor J, Almqvist KF, Bellemans J, Luyten FP, TIG/ACT/ 01/2000\&EXT Study Group. Five-year outcome of characterized chondrocyte implantation versus microfracture for symptomatic cartilage defects of the knee: early treatment matters. Am J Sports Med. 2011;39:2566-74.

9. Brittberg M, Lindahl A, Nilsson A, Ohlsson C, Isaksson O, Peterson L. Treatment of deep cartilage defects in the knee with autologous chondrocyte transplantation. N Engl J Med. 1994;331:889-95.

10. Thirion S, Berenbaum F. Culture and phenotyping of chondrocytes in primary culture. Methods Mol Med. 2004;100:1-14.

11. Jo CH, Lee YG, Shin WH, Kim H, Chai JW, Jeong EC, Kim JE, Shim H, Shin JS, Shin IS, et al. Intra-articular injection of mesenchymal stem cells for the treatment of osteoarthritis of the knee: a proof-of-concept clinical trial. Stem Cells. 2014;32:1254-66.

12. De Bari C, Dell'Accio F, Tylzanowski P, Luyten FP. Multipotent mesenchymal stem cells from adult human synovial membrane. Arthritis Rheum. 2001;44:1928-42.

13. Fickert S, Fiedler J, Brenner RE. Identification, quantification and isolation of mesenchymal progenitor cells from osteoarthritic synovium by fluorescence automated cell sorting. Osteoarthritis Cartilage. 2003;1 1:790-800.

14. Diekman BO, Rowland CR, Lennon DP, Caplan Al, Guilak F. Chondrogenesis of adult stem cells from adipose tissue and bone marrow: induction by growth factors and cartilage-derived matrix. Tissue Eng Part A. 2010;16:523-33.

15. Estes BT, Diekman BO, Gimble JM, Guilak F. Isolation of adipose-derived stem cells and their induction to a chondrogenic phenotype. Nat Protoc. 2010;5:1294-311.

16. Pittenger MF, Mackay AM, Beck SC, Jaiswal RK, Douglas R, Mosca JD, Moorman MA, Simonetti DW, Craig S, Marshak DR. Multilineage potential of adult human mesenchymal stem cells. Science. 1999;284:143-7.

17. Janzen V, Forkert R, Fleming HE, Saito Y, Waring MT, Dombkowski DM, Cheng T, DePinho RA, Sharpless NE, Scadden DT. Stem-cell ageing modified by the cyclin-dependent kinase inhibitor p16INK4a. Nature. 2006;443:421-6.

18. Muraglia A, Cancedda R, Quarto R. Clonal mesenchymal progenitors from human bone marrow differentiate in vitro according to a hierarchical model. J Cell Sci. 2000;113(Pt 7):1161-6.

19. Sakao K, Takahashi KA, Arai Y, Inoue A, Tonomura H, Saito M, Yamamoto T, Kanamura N, Imanishi J, Mazda O, Kubo T. Induction of chondrogenic phenotype in synovium-derived progenitor cells by intermittent hydrostatic pressure. Osteoarthritis Cartilage. 2008;16:805-14.

20. Li Z, Yao SJ, Alini M, Stoddart MJ. Chondrogenesis of human bone marrow mesenchymal stem cells in fibrin-polyurethane composites is modulated by frequency and amplitude of dynamic compression and shear stress. Tissue Eng Part A. 2010;16:575-84.

21. da Silva MLA, Martins A, Costa-Pinto AR, Correlo VM, Sol P, Bhattacharya M, Faria S, Reis RL, Neves NM. Chondrogenic differentiation of human bone marrow mesenchymal stem cells in chitosan-based scaffolds using a flowperfusion bioreactor. J Tissue Eng Regen Med. 2011;5:722-32.

22. Yang J, Hooper WC, Phillips DJ, Tondella ML, Talkington DF. Centrifugation of human lung epithelial carcinoma a549 cells up-regulates interleukin1 beta gene expression. Clin Diagn Lab Immunol. 2002;9:1142-3.

23. Jang Y, Koh YG, Choi YJ, Kim SH, Yoon DS, Lee M, Lee JW. Characterization of adipose tissue-derived stromal vascular fraction for clinical application to cartilage regeneration. In Vitro Cell Dev Biol Anim. 2015;51:142-50.

24. Feng J, Melcher AH, Brunette DM, Moe HK. Determination of L-ascorbic acid levels in culture medium: concentrations in commercial media and maintenance of levels under conditions of organ culture. In Vitro. 1977;13:91-9.

25. Choi KM, Seo YK, Yoon HH, Song KY, Kwon SY, Lee HS, Park JK. Effect of ascorbic acid on bone marrow-derived mesenchymal stem cell proliferation and differentiation. J Biosci Bioeng. 2008;105:586-94.

26. Jang Y, Jeong SH, Park YH, Bae HC, Lee H, Ryu WI, Park GH, Son SW. UVB induces HIF-1alpha-dependent TSLP expression via the JNK and ERK pathways. J Invest Dermatol. 2013;133:2601-8.

27. Akiyama H, Chaboissier MC, Martin JF, Schedl A, de Crombrugghe B. The transcription factor Sox9 has essential roles in successive steps of the chondrocyte differentiation pathway and is required for expression of Sox 5 and Sox6. Genes Dev. 2002;16:2813-28.

28. Furumatsu T, Ozaki T, Asahara H. Smad3 activates the Sox9-dependent transcription on chromatin. Int J Biochem Cell Biol. 2009;41:1198-204.

29. Wang CY, Chen LL, Kuo PY, Chang JL, Wang YJ, Hung SC. Apoptosis in chondrogenesis of human mesenchymal stem cells: effect of serum and medium supplements. Apoptosis. 2010;15:439-49.

30. Lefebvre V, Smits P. Transcriptional control of chondrocyte fate and differentiation. Birth Defects Res C Embryo Today. 2005;75:200-12.

31. Mackie EJ, Ahmed YA, Tatarczuch L, Chen KS, Mirams M. Endochondral ossification: how cartilage is converted into bone in the developing skeleton. Int J Biochem Cell Biol. 2008;40:46-62.

32. Dickhut A, Pelttari K, Janicki P, Wagner W, Eckstein V, Egermann M, Richter W. Calcification or dedifferentiation: requirement to lock mesenchymal stem cells in a desired differentiation stage. J Cell Physiol. 2009;219:219-26.

33. Caron MM, Emans PJ, Cremers A, Surtel DA, Coolsen MM, van Rhijn LW, Welting TJ. Hypertrophic differentiation during chondrogenic differentiation of progenitor cells is stimulated by BMP-2 but suppressed by BMP-7. Osteoarthritis Cartilage. 2013;21:604-13.

34. Bruckner $P$, van der Rest M. Structure and function of cartilage collagens. Microsc Res Tech. 1994;28:378-84. 
35. Dyment NA, Hagiwara Y, Jiang X, Huang J, Adams DJ, Rowe DW. Response of knee fibrocartilage to joint destabilization. Osteoarthritis Cartilage. 2015; 23:996-1006.

36. Smeriglio P, Dhulipala L, Lai JH, Goodman SB, Dragoo JL, Smith RL, Maloney WJ, Yang F, Bhutani N. Collagen VI enhances cartilage tissue generation by stimulating chondrocyte proliferation. Tissue Eng Part A. 2015;21:840-9.

37. Miljkovic ND, Cooper GM, Marra KG. Chondrogenesis, bone morphogenetic protein-4 and mesenchymal stem cells. Osteoarthritis Cartilage. 2008;16: 1121-30.

38. Mehlhorn AT, Niemeyer P, Kaschte K, Muller L, Finkenzeller G, Hartl D, Sudkamp NP, Schmal H. Differential effects of BMP-2 and TGF-beta1 on chondrogenic differentiation of adipose derived stem cells. Cell Prolif. 2007; 40:809-23.

39. Hildner F, Peterbauer A, Wolbank S, Nurnberger S, Marlovits S, Redl H, van Griensven M, Gabriel C. FGF-2 abolishes the chondrogenic effect of combined BMP-6 and TGF-beta in human adipose derived stem cells. J Biomed Mater Res A. 2010;94:978-87.

40. Pan Q, Yu Y, Chen Q, Li C, Wu H, Wan Y, Ma J, Sun F. Sox9, a key transcription factor of bone morphogenetic protein-2-induced chondrogenesis, is activated through BMP pathway and a CCAAT box in the proximal promoter. J Cell Physiol. 2008;217:228-41.

41. Kishi S, Abe H, Akiyama H, Tominaga T, Murakami T, Mima A, Nagai K, Kishi F, Matsuura M, Matsubara T, et al. SOX9 protein induces a chondrogenic phenotype of mesangial cells and contributes to advanced diabetic nephropathy. J Biol Chem. 2011;286:32162-9.

42. Sato M, Ochi T, Nakase T, Hirota S, Kitamura Y, Nomura S, Yasui N. Mechanical tension-stress induces expression of bone morphogenetic protein (BMP)-2 and BMP-4, but not BMP-6, BMP-7, and GDF-5 mRNA during distraction osteogenesis. J Bone Miner Res. 1999;14:1084-95.

43. Bosnakovski D, Mizuno M, Kim G, Ishiguro T, Okumura M, Iwanaga T, Kadosawa T, Fujinaga T. Chondrogenic differentiation of bovine bone marrow mesenchymal stem cells in pellet cultural system. Exp Hematol. 2004;32:502-9.

44. Zhang L, Su P, Xu C, Yang J, Yu W, Huang D. Chondrogenic differentiation of human mesenchymal stem cells: a comparison between micromass and pellet culture systems. Biotechnol Lett. 2010;32:1339-46.

45. Gao L, McBeath R, Chen CS. Stem cell shape regulates a chondrogenic versus myogenic fate through Rac1 and N-cadherin. Stem Cells. 2010;28: 564-72.

46. Iwasaki M, Nakata K, Nakahara H, Nakase T, Kimura T, Kimata K, Caplan Al, Ono K. Transforming growth factor-beta 1 stimulates chondrogenesis and inhibits osteogenesis in high density culture of periosteum-derived cells. Endocrinology. 1993;132:1603-8.

47. Awad HA, Halvorsen YD, Gimble JM, Guilak F. Effects of transforming growth factor beta1 and dexamethasone on the growth and chondrogenic differentiation of adipose-derived stromal cells. Tissue Eng. 2003;9:1301-12.

48. Mueller MB, Fischer M, Zellner J, Berner A, Dienstknecht T, Prantl L, Kujat R, Nerlich M, Tuan RS, Angele P. Hypertrophy in mesenchymal stem cell chondrogenesis: effect of TGF-beta isoforms and chondrogenic conditioning. Cells Tissues Organs. 2010;192:158-66.

49. Kim BG, Kang S, Han HH, Lee JH, Kim JE, Lee SH, Cho NH. Transcriptomewide analysis of compression-induced microRNA expression alteration in breast cancer for mining therapeutic targets. Oncotarget. 2016;7:27468-78.

50. Kanno T, Takahashi T, Tsujisawa T, Ariyoshi W, Nishihara T. Mechanical stressmediated Runx2 activation is dependent on Ras/ERK1/2 MAPK signaling in osteoblasts. J Cell Biochem. 2007;101:1266-77.

51. Tanabe $Y$, Koga M, Saito M, Matsunaga $Y$, Nakayama K. Inhibition of adipocyte differentiation by mechanical stretching through ERK-mediated downregulation of PPARgamma2. J Cell Sci. 2004;117:3605-14.

52. Kessler D, Dethlefsen S, Haase I, Plomann M, Hirche F, Krieg T, Eckes B. Fibroblasts in mechanically stressed collagen lattices assume a "synthetic" phenotype. J Biol Chem. 2001;276:36575-85.

\section{Submit your next manuscript to BioMed Central and we will help you at every step:}

- We accept pre-submission inquiries

- Our selector tool helps you to find the most relevant journal

- We provide round the clock customer support

- Convenient online submission

- Thorough peer review

- Inclusion in PubMed and all major indexing services

- Maximum visibility for your research

Submit your manuscript at www.biomedcentral.com/submit
Biomed Central 